Editorial

\title{
A New MDPI Proceedings Series Journal: Engineering Proceedings
}

\author{
Engineering Proceedings Editorial Office
}

MDPI AG, St. Alban-Anlage 66, 4052 Basel, Switzerland; engproc@mdpi.com

Received: 15 May 2020; Accepted: 15 May 2020; Published: 29 May 2020

MDPI supports open academic communication in all its forms, through the publication of research articles as well as by supporting, organizing, and communicating outcomes from conferences, seminars, and other academic meetings. It is vital to have an open record of important academic discussions, and for this reason we established Proceedings in 2017 with the aim of publishing the outputs of scholarly events. The journal has been extremely successful and we have taken the decision to create a family of proceedings journals covering different subject areas. We are therefore pleased to announce the launch of Environmental Sciences Proceedings, Engineering Proceedings, Chemistry Proceedings, and Materials Proceedings. These journals will publish proceedings papers, extended abstracts, meetings reports and editorials related to scholarly events. To date, Proceedings has published more than 4700 such pieces and we look forward to expanding this number and broadening the scope with the new journals.

Engineering Proceedings will cover the broad field of engineering. It is a research area that moves quickly and where meetings, usually involving industry and academics, are important for the exchange of ideas and translation of research into practice. By launching this journal, we aim to support researchers and practitioners by allowing anyone to have access to the very latest research insights as they are communicated.

Anyone interested in contributing to an MDPI proceedings journal should contact the editorial office. We look forward to working with event organizers and committees on this important project. 